\title{
Medicinal Plants used for Tea, Mycological and Mycotoxicological Potential
}

\author{
Sorana MATEI, Andrei SZAKACS, Adrian MACRI* \\ University of Agricultural Sciences and Veterinary Medicine Cluj-Napoca, Faculty of Veterinary Medicine, \\ 3-5 Manastur Street, Cluj-Napoca, Romania \\ *Corresponding author: adimacri@yahoo.com
}

Bulletin UASVM Veterinary Medicine 72(2) / 2015,

Print ISSN 1843-5270; Electronic ISSN 1843-5378

DOI:10.15835/buasvmcn-vm: 11463

\begin{abstract}
Mycotoxins are food contaminants with significant impact on the food industry and consumer health. Fumonisins and aflatoxins are important groups of mycotoxins, which represent secondary metabolites produced by fungi of the genera Fusarium and Aspergillus respectively.

The study was conducted on a total of 10 samples of herbal teas sold in stores and the level of aflatoxin and fumonizine content was measured. For mycotoxicological examination test RIDASCREEN@FAST Aflatoxin and RIDASCREEN@FAST Fumonisin were used, as well as competitive enzyme immunoassay tests for the quantitative determination of total aflatoxin and fumonisins in cereals and food.

Following the mycological examination, a high fungal load was found in 4 samples: rosehip tea (7.818 colony forming-unit (CFU)/g), sweet basil tea 118.636 (CFU)/g), black tea (192.272 CFU/g) and common nettle tea (204.545 CFU/g). Mycetes genus identified was Fusarium and the mycotic load surpassed by large the maximum admitted level of $100 \mathrm{CFU} / \mathrm{g}$ (Order 27/2011 ANSVSA).

Concerning the total aflatoxins, a number of 7 samples (70\%) exceeded the maximum level for total aflatoxins imposed by EU legislation (10 ppb), 3 samples exceeding even $100 \mathrm{ppb}$ value, with a maximum of $437.17 \mathrm{ppb}$ and an average of $109.21 \mathrm{ppb}$.

Values of fumonisins were comprised between $0,046 \mathrm{ppm}$ and $21,93 \mathrm{ppm}$. With the exception of St. John's wort tea, whose value of 21,93 ppm has largely exceeded the limits imposed by the European Legislation of 4 ppm, the remaining 9 samples were within the normal values.
\end{abstract}

Keywords: fumonisins, fungi, herbs, teas, total aflatoxins

\section{INTRODUCTION}

Medicinal plants are represented by cultivated plants and plants from spontaneous flora; these, due to their chemical composition, exercise favorable effects upon human organism (Temelie, 2006).

Higher consumption levels of medicinal plants and products obtained from these have triggered a problem of public health due to the unrestricted access to products inadequate for consumption. The attention concerning the quality of products obtained from medicinal plants is being thanked to the increased potential of contamination with fungi (Turner et al., 2009).
The presence of toxigenic fungi means real risk of contamination by mycotoxins. By taking into consideration the increased utilization all over the world - of the products based on plants as alternative medical substances, it is necessary to set standards to toxigenic moulds from gross plants, in order to stop these from being a menace to consumers' health condition ever. Mycetes are one large group which includes various eukaryotes comprising yeasts and moulds; these are widely spread in nature and represent common contaminants which, within favorable humidity- and temperature conditions, invade 
various food- and beverage products, by releasing mycotoxins (Binder et al., 2007).

Medicinal plants are frequently infested with toxigenic fungi coming from the soil. In many countries, there were noticed cases of infestation with mycotoxins both in medicinal plants and traditional medicinal substances obtained from these. Production of aflatoxins is influenced by several environmental factors. Important factors are represented by the substratum potential, humidity, relative humidity and fungal stem. Less important factors capable of influencing production of aflatoxins are: inoculation potential; culture potential; oxygen sourcing; interaction with insects and housing conditions. Temperature and humidity conditions in tropical - and subtropical countries are favorable to aflatoxin production (Ashiq, 2014; Santos, 2009).

Food contaminants of significant impact upon food industry and consumers' health are the mycotoxins (Zinedine and Mañes, 2009).

Important groups of mycotoxins, such as fumonisins and aflatoxins, represent secondary metabolites released by Fusarium and Aspergillus fungi (Zain, 2011).

Aflatoxins exercise important impact upon food- and feed industry as they are both highly toxic and carcinogenic to a variety of animal species (Velazhahan et al., 2010)

Concerning the wide range of toxic effects of aflatoxins and their role in human and animal mycotoxicoses, they present importance as they are not only public health peril but also causing economic losses (Razzaghi-Abyaneh et al., 2008).

Considering that medicinal teas are consumed in large quantities by the population, we found appropriate a study concerning mycological and mycotoxicological load of these plants.

\section{MATERIALS AND METHODS}

The study was carried out on 10 tea samples of the medicinal plants on markets of Cluj county: sweet basil (Ociumum basilicum); green - and black tea (Camellia sinensis); echinacea (Echinacea purpurea); fennel (Foeniculum vulgare); rose hip (Rosa canina); sage (Salvia officinalis); St. John's wort (Hypericum perforatum); lemon balm (Melissa officinalis); common nettle (Urtica dioica).

The mycological exam implies a succession of well-established stages consisting in weighing the drawn sample needed by each measurement of 10 grams, then adding $90 \mathrm{ml}$ of peptone water, followed by a recess of 30 ' and serial dilutions. This is being followed by passing to plaques on culture media incubated at 25 degrees for 5 days; reading of results follows. After 5 days of incubation, colonies are counted in each Petri dish; there are withhold only those dishes which contain below 150 colonies, but not less than 5 . Then, the colonies are counted in the two plaques belonging to each dilution followed by the identification of genera and species based on cultural traits, of the microscopic examination and comparison with dichotomic keys.

For the mycotoxicological examination, the test of RIDASCREEN@FAST Aflatoxin and RIDASCREEN®FAST Fumonisin were used, competitive enzyme immunoassay tests for the quantitative determination of total aflatoxin and, fumonisins, in cereals and food. The basis of the test is the antigen-antibody reaction. The measurement was performed photometrically at $450 \mathrm{~nm}$.

\section{RESULTS AND DISCUSSION}

Organoleptic properties evaluation revealed no alterations of the examined tea samples. Following the mycological exam carried out on the 10 tea samples analysed, there has been noticed high fungal load with 4 of the samples: rose hip tea (7.818 CFU/g); sweet basil tea (118.636 CFU/g); black tea (192.272 CFU/g) and common nettle tea (204.545 CFU/g ). Of the mycetes genera present there was Fusarium spp. (Tab. 1; Fig. 1)

The mycotic load was much higher, above the highest value accepted (100 CFU/g) (Order 27/2011 ANSVSA) (http://www.legex.ro/).

Regarding total aflatoxins, all samples were positive, the values being comprised between 2,07 ppb and 437,17 ppb.

A number of 7 samples, representing 70\%, have exceeded the maximum level for total aflatoxins imposed by European legislation (10 ppb); thus, the values being: $13,03 \mathrm{ppb}$ - echinacea; 13,96 ppb - lemon balm; 15,49 ppb - sage; 79,83 ppb rose hip; 138,43 ppb - St. John's wort; 380,48 ppb - green tea and 437,17 ppb - black tea (Fig. 2).

Three of the total aflatoxin samples have largely surpassed the accepted European legislation values (10 ppb): by more than 10 times in St. John's wort tea $(138,43 \mathrm{ppb})$; by 30 times more with green tea $(380,48 \mathrm{ppb})$ and, over 40 
Tab. 1. Genera of fungi and mycotic load in the tea samples from medicinal plants

\begin{tabular}{cccc}
\hline Sample & $\begin{array}{c}\text { Types of identified } \\
\text { fungi }\end{array}$ & CFU/g & $\begin{array}{c}\text { Specifications } \\
\text { (allowed value 100 CFU/g) }\end{array}$ \\
\hline Sweet basil & Fusarium spp. & 118.636 & Improper \\
\hline Green tea & - & $<1$ & according with the order 27/2011 \\
\hline Rose hip & Fusarium spp. & 7.818 & Improper \\
\hline Black tea & Fusarium spp. & 192.272 & Improper \\
\hline Echinacea & - & $<1$ & according with the order 27/2011 \\
\hline Common nettle & Fusarium spp. & 204.545 & Improper \\
\hline Lemon balm & - & $<1$ & according with the order 27/2011 \\
\hline St. John's wort & - & $<1$ & according with the order 27/2011 \\
\hline Sage & - & $<1$ & according with the order 27/2011 \\
\hline Fennel & - & $<1$ & according with the order 27/2011
\end{tabular}
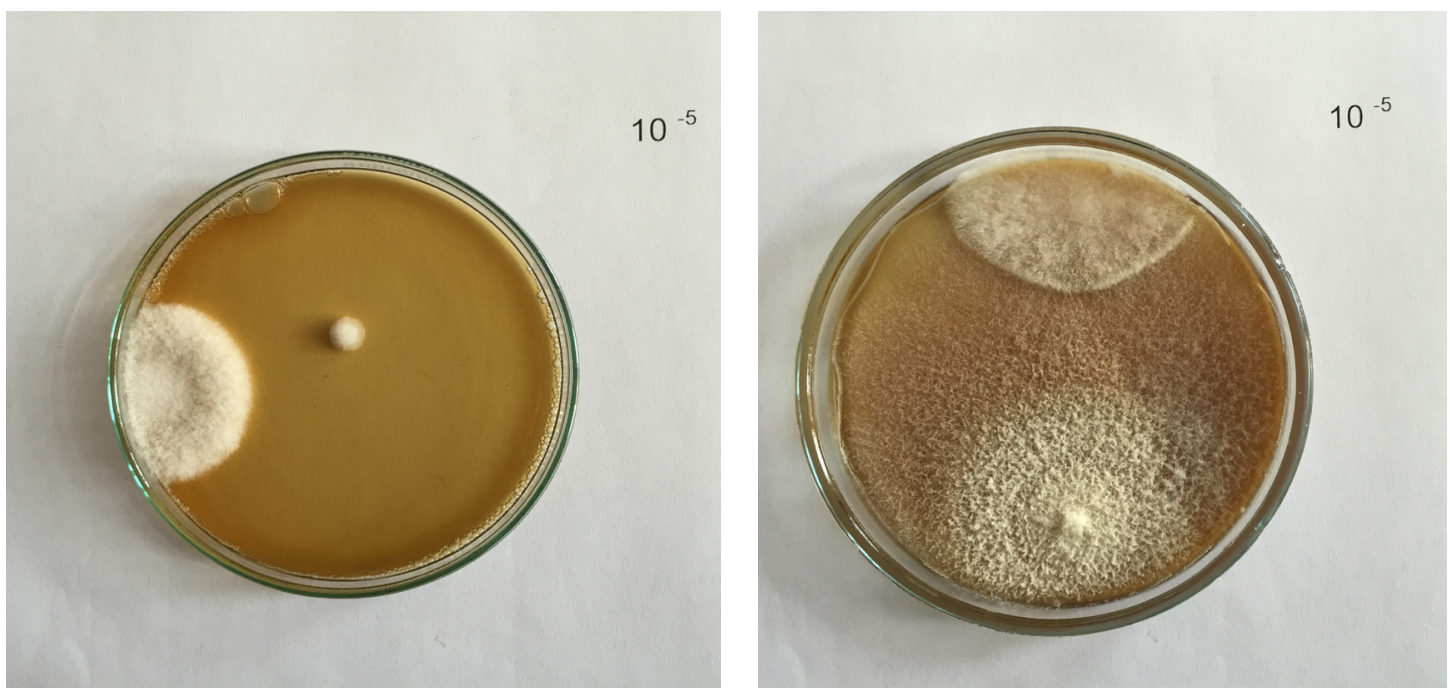

Fig. 1. Fusarium spp.

times higher than the normal values in the black tea (437,17 ppb) (Fig. 2)

Following the analyses performed in order to measure fumonisins in the tea samples, all the 10 samples were found to be positive. Values were comprised between 0,046 ppm and 21,93 ppm.

With the exception of St. John's wort tea, with which the value of 21,93 ppm has largely surpassed the limits imposed by the European Legislation of $4 \mathrm{ppm}$, the remaining 9 samples were within the normal values (Fig. 3).

A mycotoxicological screening regarding multiple contamination of medicinal and aromated teas performed in Spain has demonstrated the presence of aflatoxins, ochratoxin, deoxinivalenol and zearalenone in very high quantities in the samples analysed, the highest values of total aflatoxins values being of $853,44 \mu \mathrm{g} / \mathrm{kg}$ in a sample of red tea.

The values of mycotoxin concentrations were in many instances very differing amongst the analysed samples (Santos, 2009). Such values can be explained by the rather varied provenance of the samples, matter that we also met with and taken into study.

In 2012, Liu with a study performed on medicinal plants, have obtained a concentration of total aflatoxins of $290,8 \mu \mathrm{g} / \mathrm{kg}$. Another study carried out by Sewram, in 2006 in South Africa has shown a maximum concentration of aflatoxin $B_{1}$ in wild medicinal plants of $1553 \mu \mathrm{g} / \mathrm{kg}$, and Omurtag with Yazicioglu, in 2004, identified the presence of 


\section{Total Aflatoxin (ppb)}

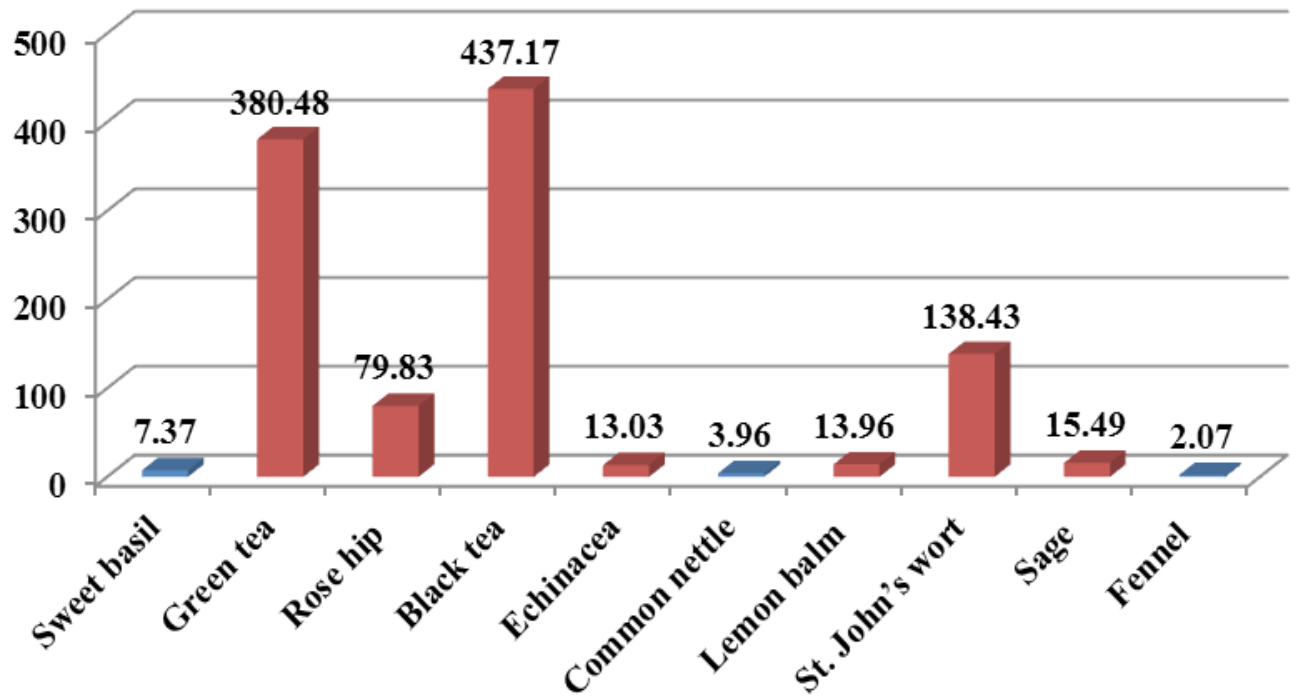

Fig. 2. Total aflatoxin values in tea samples

Total fumonisin (ppm)

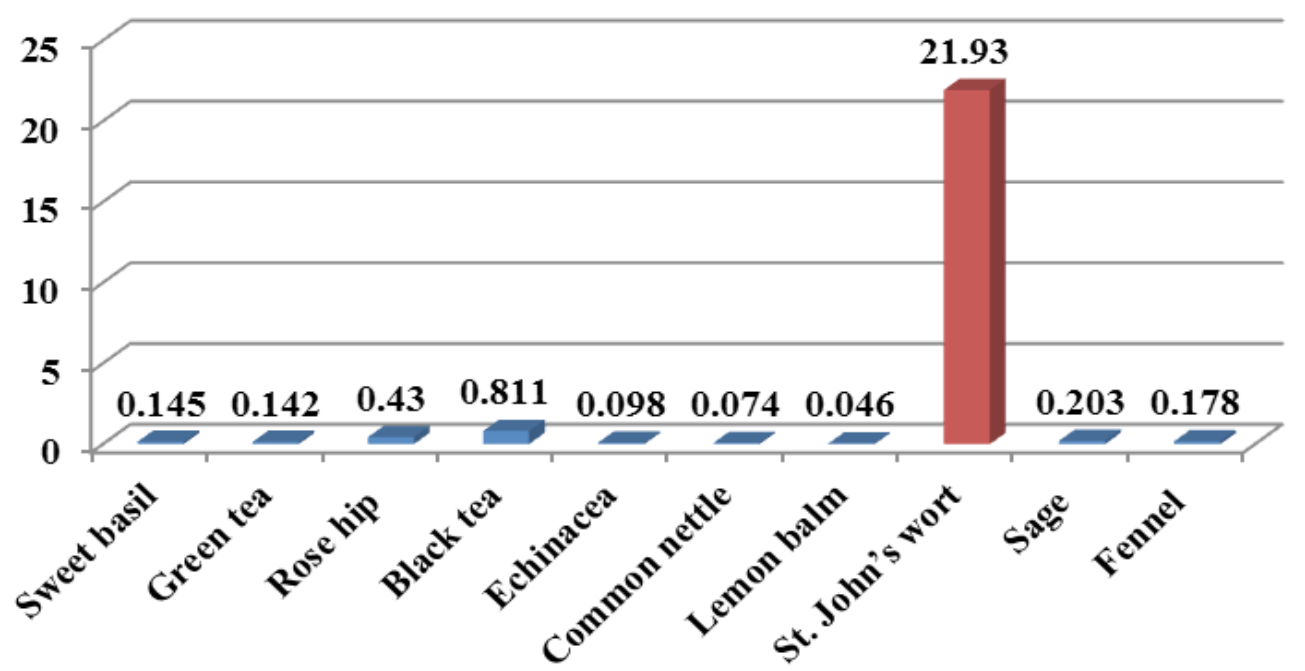

Fig. 3. Total fumonisin values in tea samples

aflatoxins $B_{1}$ in concentration of $1487 \mu \mathrm{g} / \mathrm{kg}$, in medicinal plants coming from Turkey.

\section{CONCLUSION}

Our researches have revealed a strong contamination of samples with total aflatoxins mainly in samples of green- and black tea, imported samples and we suppose that due to transportation, temperature and high humidity conditions led to the heavy infestation with aflatoxins.
Absence of mycetes in some of the samples heavily infested with aflatoxins one may explain through the fact that mycotoxins are very hardy to actions of differing agents of physico-chemical nature. One can conclude that not always can we notice a direct correlation between the mycological- and the mycotoxicological load.

\section{REFERENCES}

1. Ashiq S, Hussain M, Ahmad B (2014). Natural occurrence of mycotoxins in medicinal plants: A review.Fungal Genetics and Biology 66:1-10. 
2. Binder EM, Tan LM, Chin LJ, Handl J, Richard J (2007) Worldwide occurrence of mycotoxins in commodities, feeds and fees ingredients. Animal Feed Science and Technology 137:265-282.

3. Liu L, Liu F, W XU, Kofoet A, Humpf H, Jiang S (2005). Occurrence of fumonisins $\mathrm{B}_{1}$ and $\mathrm{B}_{2}$ in asparagus from Shandong province. Food Addit Contam 22:673-676.

4. Omurtag GZ, Yazicioglu D (2004). Determination of fumonisins $B_{1}$ and $B_{2}$ in herbal tea and medicinal plants in Turkey by high performance liquid chromatography. J Food Prot 67:1782-1786.

5. Razzaghi-Abyaneh $M$, Shams-Chahfaroki $M$, Yoshinari $T$ Rezaee MB, Jaimand K, Nagasawa H, Sakuda S (2008). International Journal of Food Microbiology 123:228-233.

6. Santos L, Martin S, Sanchis V, Ramos AJ (2009). Screening of mycotoxin multiplication in medicinal and aromatic herbs sampled in Spain. J Sci Food Agric 89:1802-1807.

7. Sewram V, Shephard GS, Van der Merwe L, Jacobs TV (2006). Mycotoxin contamination of dietary and medicinal wild plants in the Eastern Cape Province of South Africa. J Agric Food Chem 54(15):5688-5693.
8. Temelie M (2006). Enciclopedia Plantelor Medicinale Spontane din Romania. Rovimed Publishers , Bacau, 6970,363-364, 454-455, 413

9. Turner WN, Subrahmanyam S, Piletsky AS (2009). Analytical methods for determination of mycotoxins: A review. Analytica Chimica Acta 632:168-180.

10. Velazhahan R, Vijayanandraj S, Vijayasamundeeswari A, Paranidharan V, Samiyappan R, Iwamoto T, Friebe B, Muthukriehnan S (2010). Detoxofocation of aflatoxind by seed extract of the medicinal plant, Trachyspermum ammi (L.) Sprague ex Turrill- Stuctural analysis and biological toxicity of degradation product of aflatoxin G1. Food Control 21: 719-725.

11. Zain EM (2011). Impact of mycotoxins on human and animals. Journal of Saudi Chemical Society 15(2):129144.

12. Zinedine A, Manes J (2009). Occurrence and legislation of mycotoxins in food and feed from Maroc. Food Control 20:334-344.

13. http://www.legex.ro. 